\title{
A economia solidária e o valor das relações sociais vinculantes
}

\author{
Luiz Inácio Germany Gaiger \\ Universidade do Vale do Rio dos Sinos (Unisinos)
}

\section{A economia solidária e o valor das relações sociais vinculantes}

Resumo: A questão de fundo do artigo diz respeito às possibilidades contidas na economia solidária para configurar vínculos não determinados pelo cálculo utilitário e materializar um regime singular entre distintos princípios operantes na vida econômica. Para isso, apóia-se em pesquisas empíricas que demonstram a tendência da economia solidária a desenvolver relações portadoras de vínculos sociais, a partir dos quais se entrelaçam indissociavelmente a vida econômica e a vida social. Os valores emanados em tais experiências conduzem à ampliação da reciprocidade social e a envolvimentos na esfera pública, convertendo a economia solidária em agente político impulsionador de novos espaços de deliberação política, cuja perspectiva é a adoção de um sistema de regulação que garanta a coexistência de diferentes lógicas econômicas, em condições mínimas de equilíbrio. Em conclusão do artigo, argumenta-se que essa visão plural da economia requer a superação da antinomia utilitarismo-altruísmo, em favor de uma concepção híbrida das relações sociais. Palavras-chave: altruísmo, autogestão, dádiva, democracia, utilitarismo.

\section{Solidarity Economics and the Value of Binding Social Relations}

Abstract: The fundamental topic of this article is the possibility for solidarity economics to establish ties not defined by utilitarian calculations and to create a unique economic regime with distinct operating principles. To do so, it is supported by empiric studies that show the trend for solidarity economics to develop relations that carry social ties that inseparably intertwine economic and social life. The values emanating from these experiences lead to the expansion of social reciprocity and to involvements in the public sphere, converting solidarity economics into a political agent that stimulates new spaces for political deliberation. The aim is to create a system that guarantees the coexistence of different economic logics, which offer the basic conditions for equilibrium. In conclusion, the article argues that this plural vision of economics requires overcoming the utilitarian-altruist antinomy, in favor of a hybrid concept of social relations.

Key words: altruism, self-management, donation, democracy, utilitarianism. 
Este artigo retoma uma linha de entendimento e de questões suscitadas por estudos sobre a economia solidária realizados nos últimos anos ${ }^{1}$. Em sua tese principal, argumenta que as experiências de economia solidária tendem a desenvolver e acionar relações geradoras de vínculos sociais, na mão oposta dos intercâmbios de natureza utilitária e pragmática que interditam tais desdobramentos e seccionam o universo das relações, entre pessoas e grupos, da esfera das trocas materiais. $\mathrm{O}$ exame desses fatos ajuda a corrigir nossa percepção sobre o mundo atual, a superar uma espécie de visão monocromática quanto às alternativas de organização da economia e da vida coletiva. Em continuidade à tese principal, entende-se que as experiências de economia solidária ainda são instrutivas ao desbloquearem nosso olhar quanto à possibilidade de existirem efeitos positivos entre decisões 'econômicas', que afetam os seres humanos, e decisões 'sociais', que tratam de considerar os seres humanos, seja no âmbito interno das organizações, seja no plano da deliberação política sobre os rumos da sociedade.

No espaço de que dispõe, o trabalho circunscreve-se ao plano teórico e reporta suas proposições à literatura e a dados já analisados em pesquisas empíricas, das quais conviria sumariamente indicar: uma pesquisa de base nacional sobre a gênese e o perfil dos empreendimentos de economia solidária no Brasil, entre 1999 e 2003 (GAIGER, 2004); um estudo comparado de experiências há mais tempo em estudo no Rio Grande do Sul, com foco nos elementos explicativos do seu êxito em conciliar práticas de autogestão com níveis competitivos de eficiência econômica (GAIGER, 2006); análises recentes dos dados do Primeiro Mapeamento Nacional da Economia Solidária no Brasil, tendo entre seus objetivos encontrar evidências empíricas consistentes do acionamento de uma racionalidade determinada por vetores extra-econômicos (GAIGER, 2007). Esses estudos convergem com a linha de argumentação proposta neste artigo, ficando assim mais visível seu valor investigativo, enquanto voltam a se tematizarem como itens da agenda de pesquisa sobre a economia solidária e como parte da reflexão mais geral sobre a natureza e a configuração dos vínculos sociais.

Em face do crescente interesse pela economia solidária como objeto de estudo, à ciência crítica orientada por uma "hermenêutica de possibilidades" (SANTOS, 1999) cabe indagar o que significam essas formas econômicas associativas e esses protagonismos populares do ponto de vista de construções sociais alternativas. O que demanda posicionar-nos sob o prisma dos sujeitos de tais experiências, discernindo nessas trajetórias o que se opõe ou simplesmente não se subordina por inteiro ao sistema de vida dominante, no âmbito das instituições materiais e dos padrões de comportamento. De resto, não parece haver outro chão que se possa pleitear como fonte de convicção e de energia acerca de outras possibilidades humanas.

A título de preâmbulo, recapitularemos como a ordem social vigente instaurou uma percepção peculiar da economia, altamente restritiva quanto às chances de a modificarmos senão do seu interior, isto é, mediante rendição à sua lógica interna para posterior tentativa de modelar o seu desenvolvimento, conformemente às regras 'naturalmente' instituintes do campo econômico. Vencido esse primeiro passo, ficará mais claro o plano de exposição adotado nas seções ulteriores do texto.

\section{O capitalismo e o desencaixe social da economia}

Desde tempos remotos, as sociedades conheceram regimes econômicos dotados de princípios de valor e de regras sancionadas como legítimas nas esferas não-econômicas, das quais provinha a racionalidade do sistema social e suas vias de reprodução. Parcela desses arranjos convive hoje sob o manto do capitalismo. Contudo, a supremacia do "sistema mundial produtor de mercadorias" (KURZ, 1999) alterou profundamente as regras do jogo: a produção capitalista tem a peculiaridade de, uma vez acionada, gerar diretivas lógicas que se impõem a partir do próprio terreno econômico, estabelecendo uma racionalidade intrínseca que passa a digladiar-se com os demais princípios da organização social, a subjugálos quando necessário. A certa altura, tudo se passa como se realmente nada existisse fora desse movimento, salvo como obstáculo à lógica abstrata e incontornável da rentabilidade.

A força exercida pelo capitalismo explica-se por sua indiscutível produtividade e sua velocidade de inovação, por sua capacidade de fazer ruir as estruturas de amparo da sociedade, de impor à coletividade a percepção daqueles que possuem interesse expresso no livre desenvolvimento capitalista. O que conduziu a três processos sucessivos de ocultamento: quanto à existência de outras possibilidades modernas de organização da sociedade, aptas a gerar bemestar mantendo a economia embutida em sistemas de regulação politicamente instituídos; quanto à existência de outros princípios de organização econômica, não-mercantis; e quanto à existência e às virtudes de outras organizações econômicas, distintas da empresa privada capitalista (LAVILLE, 2005a).

Realidade e aparência confundem-se, de modo que a desimplicação social do campo econômico torna-se natural e inelutável. Na economia neoclássica hegemônica, a noção de riqueza cede lugar a de valor, intimamente associada, como valor de troca, ao pressuposto da escassez e ao universo utilitarista, no qual é desprezível que a ação econômica sofra o con- 
curso de sentimentos de pertencimento ou de combinações entre desinteresse e interesse. A economia distancia-se das considerações éticas e dos sentidos morais emulados a partir da vida social (SEN, 1999). Institui-se o predomínio das relações contratuais, enquanto o sistema capitalista eterniza-se nas consciências para além das condições históricas de sua gênese e reprodução.

Uma conseqüência indireta desse cenário é a inarticulação da ação política no cotidiano dos cidadãos. Os espaços públicos, suscetíveis de produzir civismo e solidariedade, são perturbados profundamente pela generalização do intercâmbio mercantil. À medida que valores e diretivas do mercado são transpostos para as relações humanas, tende-se ao enfraquecimento dos laços sociais. A questão social que se sucede é por sua vez acantonada no âmbito da benevolência privada ou transferida ao Estado, onde adquire as feições impessoais de uma solidariedade redistributiva institucionalizada.

Não faltaram advertências quanto aos riscos implicados em mudança dessa ordem e na sua aceitação unânime. Diante do reducionismo de toda a economia ao mercado, deste ao mercado auto-regulado e da produção econômica à empresa capitalista, vozes pronunciaram-se desde os primórdios do pensamento sociológico para afirmar o papel das normas sociais, da tradição e das instituições no campo econômico. A resistência e a contra-ofensiva ao paradigma do homo oeconomicus, encarnado em tempos atuais em vertentes com nome e sobrenome, tais como a Rational Action Theory e o Individualismo Metodológico, nunca deixaram de existir (LEVINE et al., 1989; WACQUANT; CALHOUN, 1991).

Uma fonte seminal nessa contenda, em favor da sociologia histórica e cultural, é Karl Polanyi (18861968), reconhecido pelo seu estudo sobre a multiplicidade de princípios que regem a vida econômica e por advogar o princípio da economia plural como uma invariante histórica. Segundo ele, em cada tempo e lugar, conjugam-se diferentes regimes. Com o capitalismo, engendrou-se um sistema tripolar, multidimensional: a economia não-monetária (fundada no princípio da domesticidade e da reciprocidade), perceptível na economia familiar e no voluntariado não remunerado; a economia não-mercantil (fundada no princípio da redistribuição), assumida modernamente pelo Estado; e a economia mercantil (princípio da oferta e demanda), que ganha preponderância através do mercado mundial (POLANYI, 1977, 2000)2 .

Interpretar as economias reais a partir da imbricação entre essas lógicas não somente reflete com provável maior adequação fatos passados da nossa história, como inverte a hipótese neoclássica de análise das condutas econômicas, levando a investigar outras esferas além da mercantil, bem como a discernir as condições sociais e políticas de prima- zia de uma ou outra lógica. Pode-se então captar em sua amplitude os experimentos sociais que fogem ao monismo do individualismo contratual. Pode-se ademais vislumbrar a adoção de um sistema de regulação que garanta a coexistência de diferentes lógicas em condições mínimas de equilíbrio, fato a ser buscado por deliberação política da sociedade, conforme se amplifiquem e se utilizem os espaços de participação democrática. Esse equilíbrio impulsionaria as formas de economia vitimadas pela extensão da economia mercantil a serem novamente exercitadas, estimulando novos arranjos econômicos e políticos.

Um arranjo dessa ordem supõe a existência de forças sociais orientadas por sua personalidade histórica, derivada do modo peculiar como atuam no campo econômico e metabolizam as condições objetivas e subjetivas correspondentes para o terreno político-ideológico. A partir das evidências de cada momento histórico, cabe inquirir as possibilidades de adveniência ou fortalecimento de princípios econômicos distintos, que caucionem outros vínculos desde o terreno de produção da vida material.

A economia solidária apresenta algumas dessas evidências, como se buscará demonstrar através do exame da natureza de suas experiências. A questão de fundo diz respeito às possibilidades contidas na economia solidária para configurar vínculos que não aqueles ditados pelo cálculo utilitário e para materializar um regime singular entre distintos princípios econômicos. Os elementos a seguir, reunidos em favor dessa hipótese, conduzirão a reconhecer o estreito entrelaçamento entre vida econômica e vida social, base da dimensão política assumida pela economia solidária, considerada adiante como uma expressão da 'solidariedade democrática'. Ao final do texto, será questionada a antinomia utilitarismo-altruísmo, em defesa de uma concepção híbrida das relações sociais.

\section{Uma experiência social da vida econômica}

A economia solidária adquire relevância porque assinala o reaparecimento do associativismo entre os trabalhadores, um fenômeno com larga história e múltiplos desenlaces (SINGER, 1998). Embora envolva categorias sociais diversas e comporte variadas formas de organização, de grupos informais e pequenas associações a cooperativas e empresas de pequeno e médio porte, o que particulariza suas experiências é o fato de eliminarem o mecanismo estrutural que separa e contrapõe os processos de produção, gestão, produção e apropriação. Como se pôde verificar por meio dos dados do Primeiro Mapeamento Nacional (GAIGER, 2007), nos empreendimentos solidários, capital e trabalho encontram-se vinculados às mesmas pessoas: os 'trabalhadores associados' 3 .

Por essa razão, a economia solidária desconhece 
ou estranha que a racionalidade econômica deva sobrepor-se a considerações sobre pessoas - a preocupações 'sociais' - ou abster-se delas. Uma segunda circunstância favorável à ancoragem social de suas experiências provém de suas condições de gênese: ao nascerem comumente em setores populares com experiência associativa, comunitária ou classista, a vivência de lutas e mobilizações cria em seus protagonistas laços de confiança e competências para defenderem seus interesses. Pelo ângulo das suas raízes econômicas, as chances de desenvolvimento dos empreendimentos crescem quando as práticas associativas são compatíveis com a economia popular típica daqueles trabalhadores, quando se amoldam aos arranjos individuais, familiares ou grupais que lhes asseguram ordinariamente a subsistência e que estão inscritos em sua experiência e nos seus círculos de relação e de influência (GAIGER, 2004).

A economia solidária não prescreve as formas populares de economia, antes se compatibiliza com elas e as potencializa, à medida que reorganiza os fatores produtivos, materiais e humanos, num processo de metamorfose apoiado em diferentes recursos e estratégias (GAIGER et al., 1999). Seguidamente, os empreendimentos de economia solidária preservam ou revitalizam relações sociais não capitalistas, fundamentais para os pobres que vivem do seu trabalho, pois atenuam sua sujeição à economia dominante e conjuram o exclusivismo das relações assalariadas, em que subordinação e expropriação são a sorte a eles reservada. A economia solidária insere-se em um padrão de experiências em que o trabalho é inseparável das pessoas e da reprodução da vida. Ora, onde o trabalho não existe como uma atividade independente, diferenciada das outras capacidades sociais do trabalhador, a troca não existe mediada apenas pelo cálculo, neutra às relações sociais e, como assinalava Sahlins (1970), separada das considerações não econômicas ${ }^{4}$.

Conforme nosso estudo comparativo de uma centena de empreendimentos no Brasil (GAIGER, 2004), quando as práticas de autogestão e cooperação aparecem de modo mais pleno, favorecem relações simétricas no tocante à posição de cada trabalhador diante dos meios de produção e ao mesmo tempo instituem uma espécie de simbiose entre inte- resses individuais e coletivos, no plano da gestão e da organização do trabalho. Essa convergência não está isenta de contradições ${ }^{5}$, mas ainda assim, no lugar de óbice à eficiência, as práticas democráticas e cooperativas impulsionam o desempenho econômico, como parte de uma racionalidade que se legitima segundo o grau de satisfação das expectativas pessoais, destituídas em boa parte do seu caráter individual. Os interesses individuais tornam-se solidários não por abnegação mútua, mas pelo aprendizado, à medida que se realizam por meio de concessões de parte a parte e ficam hipotecados a uma espécie de altruísmo recíproco, cuja contrapartida não está apenas na retribuição direta, mas nas gratificações supramateriais que proporciona.

Do ponto de vista mais amplo das relações sociais de produção, caberia ponderar que o trabalho incorporado no processo produtivo dos empreendimentos não se reveste daquelas 'mesmas' propriedades da mercadoria que lhe reserva a produção capitalista. Para guardar seu posto de trabalho, o sócio do empreendimento deixa interinamente de sujeitar-se à lei da oferta e procura, dado que não faz sentido ser tratado e tratar os demais - sócios proprietários - como mera força de trabalho negociável no mercado $^{6}$. Adicionalmente, verifica-se que as soluções encontradas pelos empreendimentos para garantir seu lugar no mercado, embora signifiquem competir pela preferência dos consumidores, não implicam subtrair os princípios do solidarismo e sucumbir à lógica utilitária. As medidas adotadas para esse fim, com perspicácia e senso de estratégia, a bem da verdade, parecem antes explorar as possibilidades conferidas pelo caráter público do empreendimento, apostando principalmente na confiança que os consumidores esperam poder nele depositar (GAIGER et al., 1999).

Vale insistir sobre essa característica dos empreendimentos, de serem indutores de ambientes e jogos de confiança. A adoção sistemática de condutas de reciprocidade na vida interna dos empreendimentos solidários incute em seus membros hábitos de cooperação, solidariedade e espírito público, formando uma "competência cívica subjetiva” (PUTNAM, 1996), além de favorecer a articulação e a agregação de interesses em âmbito mais amplo. Há, por conseguinte, uma origem interna para 
o freqüente envolvimento dos empreendimentos em lutas e mobilizações sociais: eles operam no sentido de converter a confiança, cevada no convívio cotidiano, em confiança social, que prescinde do mútuo conhecimento direto ao apoiar-se na expectativa de correspondência e restituição do equilíbrio entre as contribuições e os benefícios de uns e outros. À medida que corporificam exemplos, os empreendimentos contribuem para estabelecer um modelo para futuras colaborações, cuja reprodução age igualmente em benefício do caso exemplar, ao intensificar em sua direção os fluxos e os circuitos de ativos econômicos, sociais e políticos (GAIGER, 2004).

\section{Uma experiência política da solidariedade}

Em outras palavras, embora a razão de ser primordial dos empreendimentos solidários seja preencher as necessidades de seus membros, assim como suas aspirações de reconhecimento, inserção social e autonomia, alcançam maior êxito quando se relacionam positivamente com seu entorno. Um maior grau de solidarismo interno corresponde a maior envolvimento com as necessidades locais e com os problemas sociais em geral (GAIGER, 2006). Estarem conectados ao seu meio representa um vetor dinâmico fundamental, não um aspecto adjetivo, secundário.

A importância da ação coletiva desponta desde que os sujeitos passam a contar com um espaço comum, num primeiro momento quase sempre restrito ao próprio empreendimento. A dimensão política evidencia-se de maneira mais pujante à medida que os empreendores solidários conformam "espaços públicos de proximidade" (LAVILLE, 2004). Pela via dos embates da cidadania, a solidariedade vivida no interior dos empreendimentos externaliza-se, com chances consideráveis de transferir os princípios já internalizados, de tolerância, confiança e cooperação, para as condutas no espaço público. Nesse sentido, a economia solidária seria praticante e difusora de uma solidariedade de estilo democrático.

A solidariedade é uma construção social, repousa sobre experiências históricas, implicando sistemas de representação, modalidades de ação e estruturas de regulação. A solidariedade democrática refere-se a um estilo de ação e mobilização social fundamentado em princípios, comportamentos e dispositivos institucionais com as seguintes características ${ }^{7}$ :

- Do ponto de vista do seu contexto histórico, ela se manifesta em sociedades cujo sistema de regulação e arbitragem tenha incorporados direitos individuais e democráticos, garantidos por sua estrutura institucional e conferidos a todos os seus indivíduos e coletividades integrantes. Mas se a sociedade democrática constitui o campo de ação da solidariedade democrática, esta se ancora com freqüência em lealdades e reciprocidades prévias, cuja pregnância condiciona a racionalidade política através de um conjunto de referências e de "interesses simbólicos" (PIZZORNO, 1986).

- Do ponto de vista do seu exercício, ela decorre da atuação de indivíduos, usualmente mediante sua associação livre e voluntária, objetivando produzir benefícios sociais que correspondam à materialização ou à extensão daqueles direitos, vistos como uma aspiração legítima. O alvo da ação pode ser os seus próprios protagonistas, que nesse caso muitas vezes cultivam laços de 'reciprocidade direta' e empreendem iniciativas de cooperação mútua. Se benfeitores e beneficiários não coincidem, a ação em tese é conduzida impedindo que se criem laços de dependência e subordinação entre uns e outros, em observância aos princípios de autonomia individual e de cidadania já prescritos naqueles direitos.

- A solidariedade democrática busca acordos gerais sobre os compromissos e prioridades da sociedade. Investe assim sobre a esfera política, no sentido de reivindicar e instituir regras universais que gerem os efeitos visados, comprometendo a institucionalidade pública com a sua implantação, normatização e continuidade. Com isso, por via da alocação universal dos recursos, aponta a sistemas de 'reciprocidade social' ampliada, presumindo contrapartidas fáticas de todos os indivíduos e sobrepondo, ao desequilíbrio entre as mesmas, o primado da justiça e da igualdade entre os cidadãos.

A solidariedade democrática pode originar-se das formas anteriores de solidariedade, mas delas se distingue: supõe indivíduos reconhecidos como sujeitos dotados de livre-arbítrio e comporta iniciativas de múltiplas organizações, conscientes da insuficiência das formas precedentes de solidariedade social, assentes na comunidade, no Estado e na ação privada. Ela justifica sua designação ao apoiar-se nos preceitos e garantias do regime democrático, mas igualmente por visar à sua ampliação, desdobrando a democracia política em mecanismos de participação e estendendo-a para a esfera econômica, como reivindica a economia solidária.

As veias principais da solidariedade democrática variam segundo o contexto histórico. É possível relacionar seu revigoramento atual ao declínio das formas de mobilização classista, à crise do movimento sindical e de outras organizações similares, no contexto atual de mutações do capitalismo. Também provocam sua emergência às novas possibilidades de informação e comunicação, acessíveis sem intermediações a milhões de indivíduos anônimos, ligados por inúmeros circuitos às questões da comuni- 
dade global. Os temas mobilizadores ora decorrem da reedição ou permanência de velhas barbáries (MORIN; KERN, 1995), como a fome, a intolerância e a violência, ora de novas lutas por direitos, como aqueles dos desocupados, das minorias de todo gênero, do combate ao imperialismo globalizado e do ecopacifismo.

A economia solidária apresenta-se como uma dessas expressões. Ela metaboliza vínculos e sociabilidades primárias, imersos nas práticas da economia popular e na experiência de classe dos trabalhadores, advindos de sua posição comum no interior das relações de produção. Assumindo essas identidades e demandas, o 'movimento social' da economia solidária as alça à vida democrática, através de pressões dirigidas às esferas de decisão. As iniciativas econômicas que lhe são peculiares, determinadas igualmente por ordenamentos extra-econômicos, inserem-se, pois, no conjunto mais amplo das relações sociais por meio do debate público, no sentido de moralizar a economia, subordinando-a a valores e a normas politicamente sancionadas.

\section{A natureza híbrida das relações sociais}

Como os valores veiculados pelos atores da economia solidária invocam preceitos de justiça e igualdade, que se transladam da experiência interna dos empreendimentos para a arena pública, seria tentador, mas ilusório, preconizar uma espécie de altruísmo generalizado, capaz de banir aos poucos qualquer sinal de utilitarismo. É plausível que a economia solidária represente um caso em que a predisposição dos indivíduos a realizarem interesses não utilitários coincida com um campo de práticas que recompensa tal orientação. Mas isso não autoriza a supor que os vínculos sociais que os indivíduos nutrem todos os dias entre si para gerirem suas vidas, na interação com os seus círculos sociais, deixem de ser inexoravelmente híbridos, feitos de dosagens variadas de solidarismo, altruísmo, pragmatismo e interesse próprio (BAJOIT, 1992). O caminho consiste em reconhecer que a economia solidária espelha a presença de outros princípios de vida, historicamente encobertos pelo espírito individualista do interesse próprio, admitindo, outrossim, que condutas dirigidas ao reconhecimento e à amplificação da reciprocidade, ademais de sua orientação por valores, possam ser racionais. Esta é a chave de um modo de inteligibilidade diferente do paradigma unilateral do utilitarismo (CAILLÉ, 1994), sensível à pluralidade dos princípios motivadores da ação humana.

Estudos têm indicado razões tanto altruístas quanto individualistas, em atividades que a princípio excluiriam as últimas (REHBERG, 2005). Descartar o antiutilitarismo absoluto significa admitir que motivações utilitárias têm existência legítima e podem resolver problemas comuns, de indivíduos e coletividades. Para afastar essa visão diametralmente oposta ao utilitarismo, no qual predominaria o interesse comum ou inexistiriam razões para a adoção espontânea da lógica utilitária, poder-se-ia inicialmente reconhecer que as relações de confiança permitem mais facilmente superar o oportunismo e reduzem a ação dos aproveitadores e as perdas infligidas aos demais. As relações de confiança normalmente supõem conhecimento e julgamento positivo quanto à boa-fé e às intenções alheias. Mas não é imprescindível: basta que seja razoável esperar que a maioria, exatamente pelas vantagens que lhe proporciona ter a contrapartida dos demais ao seu gesto, respeite as regras estabelecidas. Embora imponham concessões de ambas as partes, pactos sociais de cooperação podem então estabelecer-se por mútuo acordo e tornarem-se duradouros em boa lógica de interesse próprio, desse ponto de vista sendo inteiramente congruentes e racionais para a consecução de objetivos particulares.

A presença de cidadãos virtuosos, prestativos e confiantes uns nos outros - provável efeito da situação hipotética anterior - elevaria a solidariedade social ao seu mais alto grau, sem obstar suas bases utilitárias. Tal solidariedade poder-se-ia preservar em um patamar considerável, se contasse com indivíduos razoáveis, cientes da necessidade de transacionarem seus interesses por meio de acordos. O dilema é saber quem deve começar: se os indivíduos intuem que haveria vantagem para todos se cooperassem, mas não há pactos consistentes e expectativas de reciprocidade, preferirão agir cada um por seu lado, de modo oportunista. Assim, compensando a conclusão anterior, condutas individuais estritamente utilitárias, de sujeitos perfeitamente racionais, podem gerar resultados irracionais diante dos objetivos perseguidos (PUTNAM, 1996).

De outra parte, relações brandas como aquelas do vínculo contratual, que não envolvem expectativas quanto à moral e ao comportamento alheio, a não ser quanto ao precisamente estatuído na permuta em questão, sendo então estritas e ademais passageiras, liberam os indivíduos de assumirem compromissos duráveis todo o tempo. Deixam-nos, assim, mais livres em sua intimidade moral, uma condição típica da individualidade moderna. Ademais, vínculos fracos, baseados em conhecimentos, afiliações e associações secundárias, podem ser mais importantes que os vínculos interpessoais fortes, ligados a parentesco e amizade íntima, para sustentar a coesão comunitária e a ação coletiva. Terceira conclusão: para desconcerto de quem prefere relações sempre densas em compromissos mútuos, vínculos fracos têm maior chance de unir membros de pequenos grupos diferentes ${ }^{8}$. Harmonizam-se mais às sociedades plurais e descentralizadas, 
com seus corolários de alteridade e tolerância, sendo então mais proeminentes para o fortalecimento da solidariedade democrática que perpassa e engloba as identidades singulares.

Não obstante as vantagens da colaboração entre os indivíduos nas experiências de economia solidária, o caminho para fortalecê-la não residiria na substituição do interesse próprio e das condutas utilitárias pelo desinteresse e por condutas altruístas, mas no modo como aqueles interesses podem realizar-se de forma duradoura, enquanto se alcançam objetivos comuns e se estabelecem dispositivos de partilha dos resultados. Vencido esse degrau, cria-se um fundo de interação e de confiança, a sustentar as iniciativas associativas e cooperativas concretas, segundo um modelo de "reciprocidade equilibrada" (SAHLINS, 1970), que enseja transferências de bens e acordos indissociáveis do estabelecimento de vínculos sociais e supõe a presença legítima da racionalidade econômica, como meio de assegurar a equiidade das relações ${ }^{9}$. Se no plano material imediato a soma é nula, torna-se crescente à medida que sua repetição e validação, ao longo do tempo, responde - a custos presumivelmente decrescentes - aos interesses mútuos. Utilidade e vínculo somam-se e podem conduzir à extensão dos círculos de vigência dessa forma de reciprocidade, conforme eleva-se o grau de sociabilidade subjacente entre os cooperantes, diminui a distância social ou instituem-se dispositivos sociais que asseguram tais princípios, tornando supletivos o conhecimento interpessoal e os laços primários. Amplia-se a reciprocidade social, fermento da solidariedade democrática.

\section{A presença vinculante da dádiva}

Nessa acepção, a economia solidária não ficaria reclusa no princípio de 'reciprocidade' definido por Polanyi, que o associa à dádiva e o circunscreve à economia não-monetária. A questão merece algum vagar, pois dádiva e reciprocidade são elementos coligados. Em primeiro lugar, contrariamente ao que afirmam certas críticas (HÉNAFF, 2002), a atualidade do paradigma da dádiva não reside no fato de ser uma forma primitiva de economia, autêntica em sua pureza original, abafada e recalcada com o avanço da civilização, agora em vias de ser reeditada como modelo de construção de uma outra economia, nãomercantil. Nas sociedades arcaicas a dádiva esteve apenas ocasionalmente vinculada em linha direta ao circuito das trocas materiais, à provisão dos meios de subsistência, estando de fato ligada à economia das trocas simbólicas, à distribuição do poder e à organização da vida coletiva ${ }^{10}$.

$\mathrm{O}$ valor da dádiva consiste precisamente em demonstrar que os agrupamentos humanos acionam outras racionalidades, que não a instrumental, para prover a sua existência. Outras e bem 'distintas', pois, no que tange à dádiva, sustenta-se na regra de doar em abundância, sem garantia ou expectativa 'calculada' de receber na mesma moeda, sendo a abundância o que assegura proporcionalmente o reconhecimento e o prestígio social. Não obstante as diferenças de abordagens existentes (GARDIN, 2005), aceitar a dádiva como elemento basilar da reciprocidade leva a admitir que a dádiva pura, totalmente despojada de interesse, é um caso-limite, de menor valor heurístico, sendo preferível compreendê-la em suas modalidades recorrentes, nas quais se institui um regime misto de desinteresse e interesse (CAILLÉ, 1994), em razão dos horizontes espaço-temporais em que seu ciclo se realiza.

Há coisas que o dinheiro não compra. A dádiva não sumiu, mas transformou-se, continuando a vigorar na esfera das relações pessoais diretas, mas igualmente entre desconhecidos, em função de catástrofes, do sentimento de irmandade com pessoas e povos sujeitados, ou de causas planetárias, entre os exemplos enumerados por Godbout (1999, p. 81-96) para demonstrar que a dádiva entre estranhos é tipicamente moderna. Atitudes de lealdade, cooperação e confiança, além do zelo no trabalho na ausência de vigilância e reprimendas, numa espécie quase de colaboração clandestina para a eficiência da empresa (COUTROT, 1999), manifestam o princípio da dádiva igualmente no mundo funcional das organizações, detrás das quais, como recorda Caillé (2005), sempre existem pessoas.

Importa menos a ocorrência palpável da tripla obrigação de dar, receber e retribuir, mesmo retraduzida nas condições contemporâneas. A dádiva funciona como um arquétipo do ciclo da reciprocidade, a evocar a dimensão não instrumental das relações, inclusive quando lidam com a transferência de bens. Reconhecimento e vínculo social são motivos da atividade humana e não requerem a presença desmesurada de altruísmo ou a eliminação das motivações utilitárias ou do dinheiro - hipóteses francamente extemporâneas. A dádiva ensina que há muita coisa impura, compósita, entre as antípodas do altruísmo e do utilitarismo.

Reconhecê-lo, evitando o falso problema das escolhas excludentes, favorece a compreensão das formas atuais de solidariedade, mas não assegura seu triunfo, pois a envergadura das resistências e das contraposições sistêmicas é enorme (LATOUCHE, 2003). Qualquer intento de percurso nessa direção exigiria preliminarmente rejeitar as visões monistas da ação humana e reconhecer que existem outros princípios além do interesse próprio calculado, outros comportamentos no imenso gradiente entre a coerção e a liberdade plenas. Não é outra coisa o que fazem constar a perspectiva da economia plural, no plano macrossocial, e a percepção híbrida 
dos laços sociais, no plano micro. A hipótese de ampliação da solidariedade, pela via democrática, significa ademais conceber a reciprocidade também como uma relação entre grupos desiguais, garantindo-se o equilíbrio através de um sistema institucional de regulação e arbitragem.

A razão instrumental aplicada à economia propõe soluções simples que a tornaram plausível, atraente e bem sucedida, como forma pretensamente espontânea de arbitragem. Contudo, ela possui uma contradição fatal, pois apenas preserva sua racionalidade como sistema ao preço da eliminação sistemática dos fatores que geram impasse ou perturbações à sua continuidade. Custo desprezível para quem nela se mantém, mas extremamente caro para quem o paga. Diante disso, a via que se apresenta conduz a um novo sistema de regulação, a outra institucionalização da economia (GAIGER, 2004), que discipline a liberdade imanente à conduta econômica, o que é factível somente a partir de fundamentos éticos conscientes e de uma deliberação política, como, aliás, acontece com a economia redistributiva cada vez que o pêndulo moderno inclina-se do mercado para o Estado (BERMAN, 1990). A solidariedade democrática é um dos movimentos a operar nesse sentido, de lenta e incerta alteração na relação de forças. A economia solidária representa uma de suas fontes de energia e de exemplificação.

\section{Referências}

BAJOIT, G. Pour une sociologie relationnelle. Paris: PUF, 1992.

BERMAN, M. Tudo que é sólido desmancha no ar: a aventura da modernidade. São Paulo: Cia. das Letras, 1990.

CAILLÉ,A. Don, intérêt et désintéressement: Bourdieu, Platon, Mauss et quelques autres. Paris: La Découverte, 1994.

Don. In: LAVILLE, J.-L.; CATTANI, A. (Org.). Dictionnaire de l'autre économie. Paris: Desclée de Brouwer, 2005, p. 141-7.

COUTROT, T. Critique de l'organisation du travail. Paris: La Découverte, 1999.

GAIGER, L. I. G. Economia solidária no Brasil. Porto Alegre: Ed. da UFRGS, 2004.

513-545, 2006.

Sociedade e Estado. Brasília: UNB, v. 21, n. 2, p.

. In: II SEMINÁRIO NACIONAL DO NÚCLEO DE PESQUISA SOBRE MOVIMENTOS SOCIAIS. Anais Eletrônicos. Florianópolis: UFSC, 2007.
. et al. A economia solidária no RS: viabilidade e perspectivas. Cadernos do Cedope, São Leopoldo: Unisinos, n. 15, 1999.

GARDIN, L. Réciprocité. In: LAVILLE, J.-L. ; CATTANI, A. (Org.). Dictionnaire de l'autre économie. Paris: Desclée de Brouwer, 2005, p. 419-25.

GODBOUT, J. O espírito da dádiva. Rio de Janeiro: Fundação Getúlio Vargas, 1999.

GOULDNER, A. The Norm of Reciprocity: a Preliminary Statement. American Sociological Review, v. 25, p. 161178,1960

GRANOVETTER, M. The Strength of Weak Ties. American Journal of Sociology, v. 78, n. 6, p. 1360-80, 1973.

HÉNAFF, M. Le prix de la verité; le don, l'argent, la philosophie. Paris: Seuil, 2002.

KURZ, R. O colapso da modernização; da derrocada do socialismo de caserna à crise da economia mundial. Rio de Janeiro: Paz e Terra, 1999.

LATOUCHE, S. L'oxymore de l'économie solidaire. Revue du MAUSS. Paris: La Découverte, n. 21, p. 145-50, 2003.

LAVILLE, J.-L. (Org.). Economía social y solidaria: una visión europea. Buenos Aires: Altamira, 2004.

. Economie plurielle. In: LAVILLE, J.-L. ; CATTANI, A. (Org.). Dictionnaire de l'autre économie. Paris: Desclée de Brouwer, 2005a, p. 209-16.

Solidarité. In: LAVILLE, J.-L.; CATTANI, A. (Org.). Dictionnaire de l'autre économie. Paris: Desclée de Brouwer, 2005b, p. 491-8.

LENOIR, R. Objeto sociológico e problema social. In: CHAMPAGNE, P. et al. Iniciação à prática sociológica. Petrópolis: Vozes, 1998, p. 59-106.

LEVINE, A. et al. Marxismo e individualismo metodológico. Revista Brasileira de Ciências Sociais, São Paulo: ANPOCS, v. 4, n. 1, p. 57-70, 1989.

MORIN, E.; KERN, A.-B. Terra-Pátria. PortoAlegre: Sulina, 1995.

PIZZORNO, A. Sur la rationalité du choix démocratique. In: BIRBAUM, P. ; LECA, J. Sur l'individualisme. Paris: Presses de la FNSP, 1986, p. 330-369.

POLANYI, K. The Two Meanings of Economic. In: PEARSON, H. The Livelihood of Man. New York - San Francisco - London: Academic Press, 1977, p. 19-34. 
A grande transformação; as origens da nossa época. Rio de Janeiro: Campus, 2000.

PUTNAM, R. Comunidade e democracia; a experiência da Itália Moderna. Rio de Janeiro: Fundação Getúlio Vargas, 1996.

REHBERG, W. Altruistic Individualists: Motivations for International Volunteering Among Young Adults in Switzerland. Voluntas - International Journal of Voluntary and Nonprofit Organisations. Dordrecht, v. 16, n. 2, p. 109-122, 2005.

SAHLINS, M. Sociedades tribais. Rio de Janeiro: Zahar, 1970.

SANTOS, B. de S. Porque é tão difícil construir uma teoria crítica? Revista Crítica de Ciências Sociais. Coimbra: Centro de Estudos Sociais, n. 54, p. 197-215, junho, 1999.

SEN, A. Sobre ética e economia. São Paulo: Cia. das Letras, 1999.

SERVICE, E. The Hunters. New Jersey: Prentice-Hall, 1966.

SINGER, P. Uma utopia militante. Rio de Janeiro: Vozes, 1998.

WACQUANT, L.; CALHOUN, C. Interesse, racionalidade e cultura. Revista Brasileira de Ciências Sociais. São Paulo: ANPOCS, v. 6, n. 15, p. 76-93, 1991.

\section{Notas}

1 No âmbito do Programa de Pós-Graduação em Ciências Sociais, da Universidade do Vale do Rio dos Sinos, com apoio do CNPqe daFAPERGS (www.ecosol.org.br).

2 A tese de Polanyi compreensivelmente é objeto de controvérsias, com ampla bibliografia a respeito, especialmente no âmbito da Nova Sociologia Econômica.

3 Embora variável e sujeita a reversões, essa é a qualidade teoricamente definidora da economia solidária e não, como muitas vezes se dá a entender, a simples proliferação de arranjos formalmente cooperativos e associativos, cujo caráter efetivo, do ponto de vista do igualitarismo e da autogestão, obviamente resta a verificar. Como introdução a essa discussão conceitual, recomendamos a obra organizada por Laville e Cattani (2005). Os dados mais recentes e abrangentes sobre o perfil e as práticas da economia solidária encontram-se no Atlas da Economia Solidária, disponível no website do Ministério do Trabalho e Emprego.

4 Separação para a qual contribuíram por sinal as próprias ciências sociais (LENOIR, 1998).
5 A começar pela necessidade de decidir sobre novas questões em aberto: distinguir e compatibilizar as necessidades de acumulação e de investimento do empreendimento (isto é, do 'capital'), com as necessidades e interesses dos seus associados (isto é, do 'trabalho'); canalizar para o empreendimento os ganhos gerados pelos esforços do conjunto de trabalhadores, tornando tais ganhos essencialmente coletivos, e reconhecer ao mesmo tempo as diferenças entre os aportes individuais (GAIGER, 2006).

6 Não obstante as contingências da realidade econômica não liberarem o empreendimento de ater-se ao princípio da média de trabalho socialmente necessário para a produção dos bens em questão e aos efeitos da concorrência daqueles que, precisamente na mão inversa, empregamo trabalho como mercadoria, sem hesitar em deprimir o seu valor se for mais conveniente para o mercado.

7 A expressão, como tal, a retomo de Laville (2005b). Sua elaboração aqui é inspirada em intercâmbios com pesquisadores de diferentes países, principalmente JeanLouis Laville, Laurent Fraisse (França), Guy Bajoit, Jacques Defourny (Bélgica), José Luis Coraggio (Argentina), Paul Singere Genauto França Filho (Brasil).

8 Ver a respeito Granovetter(1973, citado por Putnam, 1996,p. 185).

9 A classificação das formas gerais de reciprocidade é retomada por Sahlins de dois autores: Gouldner (1960), para o conceito de reciprocidade negativa; Service (1966), para todo o gradiente.

10 Outrossim, como as modalidades da dádiva dependiam da distância social e espacial, intimamente ligada aos laços de parentesco, pelos quais organizava-se o acesso aos meios de produção e de subsistência, há uma congruência inegável, mesmo indireta, entre o universo cerimonial da dádiva e o universo pragmático da materialidade.

\section{Luiz Inácio Germany Gaiger}

Doutor em Sociologia, Université Catholique de Louvain

Coordenador do Programa de Pós-Graduação em Ciências Sociais, da Universidade do Vale do Rio dos Sinos (Unisinos)

Coordenador da Cátedra Unesco-Unisinos Trabalho e Sociedade Solidária

Membro da Coordenação da Red de Investigadores de Economía Social y Solidária (Riless)

Programa de Pós-Graduação em Ciências Sociais da Unisinos

Av. Unisinos, 950

São Leopoldo - Rio Grande do Sul

CEP: 93022-000 